\title{
Zirconium Zr 89-Df-IAB22M2C
}

National Cancer Institute

\section{Source}

National Cancer Institute. Zirconium Zr 89-Df-IAB22M2C. NCI Thesaurus. Code C137822.

A radioimmunoconjug ate comprised of a minibody ( $\mathrm{Mb})$, an inert antibody fragment against the human CD8-antigen on CD8-positive T-cells, conjug ated to the chelator desferrioxamine (Df) and labeled with the radioisotope zirconium Zr 89, with potential positron emission tomog raphy (PET) imaging activity. Upon administration of zirconium Zr 89-Df-IAB22M2C, the Mb moiety specifically targets and binds to the CD8 antigen expressed on T-cells. This enables PET detection of the radioisotope moiety, and may allow the imaging, tracking and quantification of CD8-expressing T-cells. This may detect CD8-positive T-cell distribution and activity, and may help determine the patient's response to cancer immunotherapeutic agents. CD8-positive T-cells play a key role in the eradication of cancer cells. Although the Mb has the same antigen specificity and binding affinity as the full-length antibody, the Mb does not activate or induce the proliferation of CD8-positive T-cells. 